\title{
Hydrocarbons Aromatics and Polynuclear Aromatics in sediments Contaminated with Oil Drilling in Coastal Plain of the Mexican Southeast
}

\author{
Raúl Uribe-Hernández*, Marco Alejandro Montes de Oca-García, \\ Victor Emigdio Martínez-Martínez, Juan Antonio Zermeño-Eguía Lis, \\ Andrés Rosas-Molina, \\ Instituto Mexicano del Petróleo, Eje Central Lázaro Cárdenas,Cd. de México, México.
}

\begin{abstract}
One of the important activities of the oil industry is drilling for exploration and prospection, during this activity drilling fluids are used and later are formed as waste large volumes called drill cuttings. When inverse emulsion fluids are used it is common to use diesel light oil which increases the content of hydrocarbon impregnated drill cuttings. The aim of the research was to evaluate the concentrations of BTEX and PAH present in sediments associated with oil drilling cuts an environmental liability in southeastern Mexico. Within the dam, the unique values of BTEX were recorded in sediment, they were presented in well PM2 levels 1 and 2 deep. In relation to PAH levels in the dam cuts, only five compounds of this group were presented with the following maximum concentrations: Naphthalene 24.3, Acenaphthene 12.9, Fluorene 14, Phenanthrene and Pyrene $44.72 \mathrm{mg} / \mathrm{kg}$. While in exploration wells, located in the dam adjacent to the outer area, BTEX and $P A H$ concentrations nor were presented, both in sediment samples as in ground water. Situation attributed to the mudecake phenomenon of the walls of the dam, due to the precipitation of PAH and material flow in function to the size from the sand, silt and end clays end of sealing the pores of the walls. Finally produce an effect of trapping of these materials in the oil drilling cuts dam, a situation that has avoided adverse effects on the environment directly and indirectly to the biota in the area.
\end{abstract}

Keywords: BTEX, PAH, drill cutting, sediment, oil drilling, mudecake, environmental liability

Abbreviations: PAH -Polynuclear aromatic hydrocarbons, BTEX-Benzene, Toluene, Ethylbenzene and Xylenes, MW-Monitoring Well, EW-Exploration Well

\section{INTRODUCTION}

Petroleum hydrocarbons persist after many decades the tropical wetland sediments. Wetlands and swampy areas are considered coastal areas with ability to maintain hosted the oil from spills or Safety of oil for long periods. Different environmental processes both the fate of the oil in these environments interacts with each other resulting in this permanence over time [1]. Many organic pollutants are less available to advance the degradation in the soil or soils are subjected to treatment. In addition, the presence and nature of the organic matter in the soil or sediment may have a profound influence on the availability of contaminants such as polynuclear aromatic hydrocarbons (PAH).

This reduced availability, can result from chemical interaction or being trapped in very fine pores of the subsoil, can have an important in the determination of the levels effect cleaning to protect environment and remediation goals and therefore should be reflected in the evaluation of environmental risk for the disposal of waste and the actions arising from the same [2].

The activities of drilling for oil and gas exploration occur in solids liquids and gases, which may have adverse environmental effects; between these residues is have those hydrocarbons, metals heavy, and salts, among others. Drilling cuts are produced from the use of drilling fluids used in such operations for the exploration of oil and gas deposits, with the aim of removing drilling (fragments of rock of the drilled well) cuts and control of pressures of training [3]. Other important functions are seal permeable formations, maintain the stability of the drilled well, cool and lubricate the drilling bit, and transmit hydraulic energy drilling instruments and the drilling bit.

Drilling well produced cuts and drilling fluids used, tend to be the most important residual currents between those generated during drilling of oil and gas activities. There are many types of drilling 
fluids, but all of them, generally fall within one of these two systems of fluids. Aqueous drilling fluids: phase continues and the suspension to the solid (or liquid) medium is water or water miscible fluid. There are many varieties of drilling fluids aqueous gel and polymer/salt, salt/glycol salt/silicate. And non-aqueous or inverse emulsion drilling fluids: in which phase continues and the means of suspension for solids (or fluids), is a non-miscible fluid in water in base oil which was used diesel or light oil fractions, enhanced mineral oil or synthetic base oil is currently used [3].

Drilling cuts must be removed from the well as they are generated by the auger. For this purpose, circulates a drilling fluid and drill through the auger, which drags and carries the cuts until the surface, climbing through the annular space. Removal of cuts (the hole cleaning) depends on the size, shape and density of the cuts, the rotation of the column of drilling and viscosity, density and speed void [4] drilling fluid.

The waste more abundant generated during the drilling of wells of gas and oil are them cuts of drilling, these contain hydrocarbons aromatic polynuclear (PAH) and certain metals heavy (mainly $\mathrm{Ba}$, and with levels much more low of $\mathrm{Cr}, \mathrm{Fe}, \mathrm{Ca}, \mathrm{V}$, or and $\mathrm{Zn}$ ), and are usually of nature Basic (USEPA, 2000). Produced water and petroleum oils also contain varying concentrations of PAH and monoaromatics compounds (BTEX) volatile which may present toxicity (USEPA, 2000). In Mexico, these residues are considering special management under the current regulations of the General Law for the Integral management of residue [5], by what must be treated or disposed in a controlled way. This environmental liability are associated to oil drilling well since thirty-five years ago.

Tropical wetlands boast a vast biological diversity, a great temporal variability in their environmental parameters, as well as the receipt of large amounts of organic material of terrestrial origin and along with these, can accommodate different substances of anthropic origin [6]. Due to its ubiquity and persistent nature, soil and sediment are an effective reservoirs in which PAH are housing. PAH in soil can lead to direct or indirect exposure in humans. Studies dealing with pollution and remediation of soil by PAH, are therefore crucial for the protection of the environment and human health in the environment that lives.

The study site is located in the southeast of Mexico in the State of Tabasco (Figure 1). The evaluated area is located in the county of Centla, Tabasco. The study area is located at $10 \mathrm{~m}$ to altitude. The climatology of the area according to the classification of Koopen, presents three types of climates: Aw "GI, Amw" ig and Am (f) w"(i) g, which are referred to the climatological stations in the proximity to the zone.

The climate in the region of the study area is hot wet and is in the basin of the Grijalva River, which presents maximum rainfall at the national level, being the seasons of summer and fall the rainiest [7]. The average annual temperature in the coastal area of Tabasco is $27^{\circ} \mathrm{C}$ and the average maximum temperature is $36^{\circ} \mathrm{C}$ during May and the average minimum is $18.5^{\circ} \mathrm{C}$ in January [8].Generally the climate goes humid with rains in summer to semi warm-sub humid with rains in summer and usually rains extend up to autumn and winter as mentioned above. The precipitation that is concentrated in the summer and the autumn is associated to the time of hurricanes both from the Pacific as of the Gulf of Mexico [9].

The study area is located in the Tabasco State, the physiographic province of the coastal plains in the South of the Gulf of Mexico (Fig.1). This province is characterized by gradual fills of tertiary age detritus material (floodplain) and is characterized by eroded areas of low elevation (up to $60 \mathrm{~m}$ heights) predominantly sandstone hills and some outcrops of limestone inland. This area is a source of great and different fluvial deposits as the lake, marsh and littoral linked to extensive plains of flood, abandoned runways and coastal lagoons.

This region of the State of Tabasco is characterized by its soft topography, where those swamps, lagoons and lakes permanent constitute more than the third part of the system river of them rivers Grijalva and Usumacinta [8]. Some authors also known as sub province of plains and swamps Tabasco, the rest of the area is covered by material recent except by some outcrops of the Eocene. Oligocene and Miocene in the end are of the province [10]. (Fig.1). 
Hydrocarbons Aromatics and Polynuclear Aromatics Insediments Contaminated with Oil Drilling in Coastal Plain of the Mexican Southeast

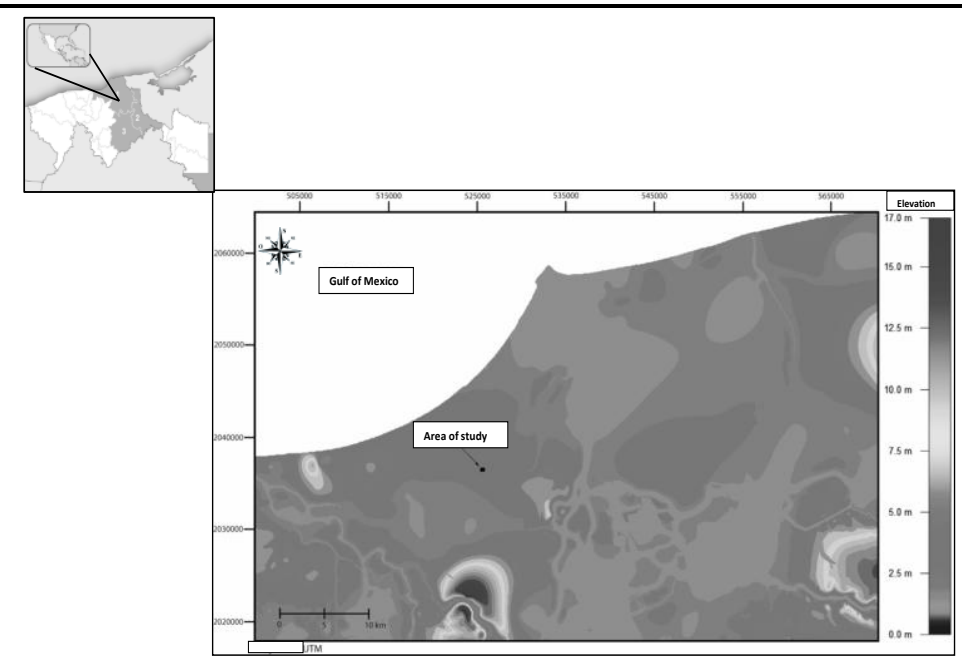

Figure1. Digital elevation model (DEM) with vector data that shows the topography and elevations in the study area and surrounding areas (CENAPRED, 2008).

The model of faces and stratigraphy, within this sedimentary environment, of a wave-dominated delta progradation is a typical succession of faces according to each sub-environment: prodelta, delta, beach and plain bars or laces front deltaic in ascending order [11]. It increases the influence of the wave bar or beach cords covering the Delta front deposits are developed.

The objective of the research was evaluate them concentrations of BTEX and PAH present in cuts of drilling oil in a passive environmental in the Southeast Mexican. Was did sampling stratified and use of wells of reference in the perimeter of the dam of drill cuts, as well as of parameters of physicochemical of sediment, to define it dispersion of the pollution.

\section{MATERIALS AND METHODS}

Sampling field activities began in first instance, with the recognition of the site, in order to get information regarding the physical conditions in the wetland, both areas shallow as well as flood in your periphery. For defined the plan of stratified sampling, was included the spatial distribution of the sampling points, both inside the dam as in its outer perimeter whereas two determinants of variability. On the one hand the surface distribution of sediment in the dam and the location with respect to the edges of it, and on the other hand the stratified sampling at depth, whereas the presence or ostensible absence of cuts impregnated with oil, in each sampling wells.

The location of the external to dam exploration wells was determined using as a criterion, the direction of groundwater flow, placing a well water up and two downstream, for both collecting sediment and groundwater, considering that the total area of the dam is $6,475.24 \mathrm{~m}^{2}$, UTM coordinates: 525600 and 2036400, same that are shown in the Figure 2.

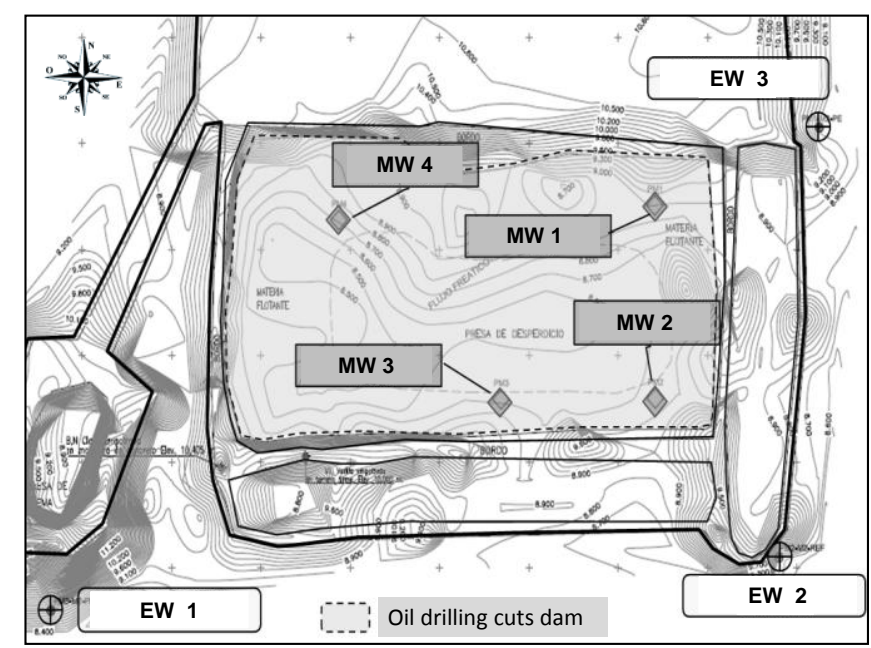

Figure2. Area of the dam cuts in drilling, with the location of wells of sampling inside and outside prey exploratory wells, used as a reference for comparison purposes. 
Four sampling wells located within the dam were identified as: MW1, MW2, MW3 and MW4, these collected samples at four depths between the $0.00 \mathrm{~m}$ and $2.80 \mathrm{~m}$, detail from each of these points is mentioned in table 1 . In order to evaluate the possible transport of contaminants out of the limits of drilling cuttings dam, were and built 3 exploratory wells (piezometers), first for sediment sampling and then casing once you collect groundwater, wells were identified as: EW1, EW2 and EW3. In the case of the exploratory wells only were sampling to a depth, which determined the level of underground water, once performed casing well recovery and abatement.

Table1. Wells type and depth (meters) of sampling in the sediment, for each so well inside and out of the debris dam.

\begin{tabular}{|c|c|c|c|c|c|c|}
\hline MW1 & MW2 & MW3 & MW4 & EW1 & EW2 & EW3 \\
\hline 0 a 1 & 0 a 1 & 0 a 1 & $0 \mathrm{a} 1$ & & & \\
\hline 1 a 2 & $1 \mathrm{a} 1,9$ & $1 \mathrm{a} 1,3$ & $1 \mathrm{a} 1,4$ & $1 \mathrm{a} 2$ & $1 \mathrm{a} 2$ & $1 \mathrm{a} 2$ \\
\hline $2 \mathrm{a} 2,2$ & $1,9 \mathrm{a} 2,2$ & $1,3 \mathrm{a} 1,5$ & $1,4 \mathrm{a} 1,6$ & $2 \mathrm{a} 3$ & $2 \mathrm{a} 4$ & $2 \mathrm{a} 3$ \\
\hline $2,2 \mathrm{a} 2,8$ & $2,2 \mathrm{a} 2,7$ & $1,5 \mathrm{a} 2,1$ & $1,6 \mathrm{a} 2,1$ & & & \\
\hline
\end{tabular}

Monitoring well $(M W)$, exploratory well $(E W)$. Deep in meters $(m)$

The collection of samples was performed with a manual corer type hand auger of stainless steel, with extensions of approximately $1.2 \mathrm{~m}$, to reach the established depth. This point the sample was taken directly from the corer with a spatula for stainless steel, emptying it in the container glass and Teflon cap, which was tagged and kept at $4{ }^{\circ} \mathrm{C}$ until analysis.

Water samples were collected directly in each one of the exploratory wells, after having been casing, purged and were left to stand for 24 hrs., collecting disposable sampler type Bailer of PET material and packaging in glass with Teflon cover jars, labeled, stored at $4{ }^{\circ} \mathrm{C}$ for transport and shipping to the appropriate laboratory with a tube. There were data from groundwater and with details of the location of the piezometers in the study area, are interpolated the isovalues curves of equal depth of the piezometric level, whereas the average of the three measurements made. Curves obtained shows that the direction of preferential flow w-e, whereas the flow moves in the direction of the hydraulic load.

The samples were preserved in amber glass bottles in order to avoid a possible cross-contamination, were stored in refrigeration at $4{ }^{\circ} \mathrm{C}$. The sediment samples were sieved through a $2 \mathrm{~mm}$ mesh before was the separation of fragments of rock, residual roots and unwanted, and then materials were homogenized and after sealed with a Teflon cover and kept in the refrigerator until analysis of hydrocarbons. Samples $(5 \mathrm{~g})$ mixed with anhydrous sodium sulfate and extracted Sox hlet using a solvent mixture of hexane-Dichloromethane (1:1).

Extraction time was $8 \mathrm{~h}$, after which the organic extracts is evaporated on a rotary evaporator to $5 \mathrm{ml}$. Prepared the chromatographic columns with silica gel and deactivated with deionized water (5\%) aluminum oxide and one coating finish with anhydrous sodium sulfate. The samples was did pass through the columns, then them PAH is eluted with a mix of hexane and dichloromethane (9:1 and 1:1). Organic extract concentrated on a rotary evaporator to $1 \mathrm{ml}$ and transferred to a vial for gas chromatography analysis according to method EPA 3550[12].

The EPA- 8260 method was used to determine the volatile organic compounds included the BTEX in a variety of solid waste matrices. Techniques by which these compounds can be introduced in the system of gas chromatography with mass spectrometry (GC/MS), are through the techniques of purge and trap, 5030 methods (aqueous samples), is the most common technique used for analyses organic volatile. For the analysis of BTEX compounds, enters the sample the gas chromatograph by purge and trap method directly to the capillary column.

The temperature of the column is scheduled to separate the analytes that are detected with a spectrometer (GC/MS) in the case of MS, the analytes eluates are introduced to the source of ions of the mass spectrometer through an interface to the ion source. Quantification was done by comparing the response of characteristic ions related to an internal standard using a calibration curve with 5 points as a minimum [13].

The analysis of PAHS in sediment and water were realized with EPA 3550 / EPA 8270D.The procedure for low concentrations, the sample is mixed with anhydrous sodium sulfate to form a freeflowing powder. The mixture is extracted with solvent (acetone/1:1 methylene chloride) three times, 
using ultrasonic extraction. The summary is separated from the sample by vacuum filtration or centrifugation. The extract is ready for the final concentration, cleaning and analysis (USEPA-3530).

The semi-volatile compounds were analyzed into the GC/MS, injecting the extract of the sample into a gas chromatography (GC) with a capillary column of fused silica of narrow gauge. Identification of analytes is accomplished by the comparison of their spectra spectra of masses with the electron impact (or electron impact-like) of authentic standards. And finally the quantification is performed by comparison of the response of a greater ion (quantification) in relation to an internal standard with a calibration of five points (EPA-8270) [14].

The physico-chemical properties of the soil were determined in accordance with the methodologies established in the Mexican standard official (NOM-021-RECNAT-2000) [15], in laboratory: apparent density (the test tube method) and texture (Bouyoucos method). The chemical variables analyzed were: $\mathrm{pH}$ (potentiometer soil:water 1:2 ratio), percentage of organic matter (Walkley and Black method), inorganic nitrogen (extracted with $2 \mathrm{~N}$ potassium chloride and steam-driven), phosphorous (Olsen method). Exchangeable cations $\mathrm{K}, \mathrm{Ca}, \mathrm{Na}$ and $\mathrm{Mg}$ (extracted with $1 \mathrm{~N}, \mathrm{pH} 7.0$ ammonium acetate) and extractable concentrations of potentially toxic elements: cadmium, copper, manganese, nickel, lead and zinc; quantified by atomic absorption spectrophotometry.

The interpretation of the results of the physical and chemical soil analysis (data not showed) was by comparison with the values specified in the NOM-021-RECNAT-2000. Not included in these Mexican standard physical variables, and were interpreted by reference to the values of reference of exploratory wells (EW) of this study.

\section{STATISTICAL ANALYSIS OF THE RESULTS}

All analyses of made in triplicate the interpretation of the contents of hydrocarbons in the contaminated sediment with wells of sampling (MW), was carried out by comparison with the results of the exploratory wells (EW) reference sediment. Applied analysis of variance analysis and means comparison test was with minimum difference $(\mathrm{p}<0.05)$ with the program SPSS version 20 [16].

\section{RESULTS AND DISCUSSION}

The results of analysis physico-chemicalof the samples obtained of sediment through the drilling of them 4 wells of monitoring (MW), and in the areas surrounding is obtained of them 3 wells exploratory $(\mathrm{EW})$, (data not showed) presented in general differences statistically significant ( $\mathrm{p}<$ 0.05). Except the case of texture and $\mathrm{pH}$, to compare the values of each parameter between the two groups of wells, MW and EW.

The $\mathrm{pH}$ in them samples of sediment of them MW is found in an average of 8.58 units within the dam, representing a material strongly alkaline, and an average of 8.28 units in them wells exploratory, being moderately alkaline (Muñoz, 2007). This means that alkalinity may be caused by the presence of drilling muds whose composition could contain salts of barium sulfate.

The electrical conductivity (EC) presented an overall average of $2.04 \mathrm{dS} / \mathrm{m}$ in sediments of the dam and $1.47 \mathrm{dS} / \mathrm{m}$ in soils of the exploratory wells. Both values correspond to a category not saline [9]. The low salinity is must basically to the area belongs to an area tropical whose abundance of rain can drag them sales by them runoff surface and groundwater, the low salinity can be remnants of sludge saline of drilling, used in the last for the drilling of the well.

The organic matter in sediment average was $8.63 \%$, which means that the material is considered rich in organic material, however the high value may be due to the high content of hydrocarbons from fraction medium and heavy hydrocarbons present in the punching breaks. Unlike the sediments of the exploratory wells, this presented one value less than $2.54 \%$ of organics in each well, the means that it is poor in material organic. This related to the soil is formed by arenas in more than $82 \%$, and this type materials in sediments, virtually lacks natural organic compounds, as in tropical presenting fulvic acids and humic soils.

In the case of these sediments, organic matter value corresponds to a material of type pathogenic rain tight, which was deposited forming layers of stone material of the rock ground in lenses the same petroleum hydrocarbons and inverse emulsion drilling fluids and drilling. 
With respect to both sediment and soil textural class is practically sandy from the relative percentage of particles correspond to fine sand $(>88 \%)$ and with a low percentage of silt $(<8 \%)$ and clay $(<4 \%)$. Only the sediment of the exploratory well EW2 presented sand-crumbly texture with $82.76 \%$ sand, $6 \%$ silt and $11.24 \%$ clay (Muñoz, 2007). The high proportion of sands means that the soil has a low fertility, high porosity and high permeability $\left(10^{-5}\right.$ to $\left.10^{-3} \mathrm{~cm} / \mathrm{sec}\right)$. This permeability should encourage the flow of groundwater and with this, contaminant transport, status that was not observed.

Based on the values of the hydraulic gradient in the direction of estimated flow according to the piezometric data, the value of permeability was: $9.420 \times 10^{-4} \mathrm{~cm} / \mathrm{s}$, same, which agrees with Tin, obtained porosity. With this observation was inferred to exist contaminant transport from the dam they should be present in the exploratory wells off the dam fact that did not happen.

The texture gives us an indirect feature both permeability as well as the potential for delay, both minerals and hydrocarbons non-polar such as PAH. From these values, the potential of dispersion can be set or theoretical delay in sediments, in this case high levels low percentage of clays and Sands mean a high permeability, with associated values of permeability. Considering geological features described above, the dominantly coarse grain sizes well identified at least in the first $5 \mathrm{~m}$ of depth, are presented shoelaces or coastal bars.

In relation to the total nitrogen a macronutrient like phosphorus and potassium, this is because they are elements or compounds of greater consumption by vegetation and soil microorganisms. In the results you can see an average of $0.27 \mathrm{mg} / \mathrm{kg}$ for sediment of MW, since these are sandy and low content of organic matter. These values were considered poor (Muñoz, 2007). In these general terms the sediment is shallow for the biota, which determines another condition of delay in the carriage of hydrocarbons due to their interaction with the root systems of vegetation, as well as an inherent process of degradation by microorganisms associated.

Similarly in the case of phosphorus is also a macronutrient and is required by plants for their proper development. Values of available phosphorus usable classified soil and sediment into a poor category $(<4 \mathrm{mg} / \mathrm{kg}$ ) (Muñoz, 2007). This element may occur in organic form (combined with $\mathrm{Ca}, \mathrm{Fe}$, and the) and inorganic (less common) therefore, it was determined that the phosphorus extractable or inorganic is an average of $84.56 \mathrm{mg} / \mathrm{kg}$ for sediment of MW with $180.40 \mathrm{mg} / \mathrm{kg}$ for the surrounding sediments $(\mathrm{EW})$, which is interpreted as high in both.

The average of total phosphorus in sediment is $94.76 \mathrm{mg} / \mathrm{kg}$ in $\mathrm{MW}$ and the average floor is 139.49 $\mathrm{mg} / \mathrm{kg}$ in EW. In these general terms of nitrogen and phosphorus, sediments are of medium fertility to the biota, which determined another factor of delay in the carriage of hydrocarbons, due to its interaction with the root systems of vegetation, as well as an inherent process of biodegradation by microorganisms associated.

Total organic carbon (TOC), is associated with organic matter, since they are related by a mathematical factor, so that the TOC multiplied by this factor, resulting in their conversion to organic matter. In the case of sediments, the TOC has an average of 5.0\% in PM, while soils have an average of $0.40 \%$ in PE. The interpretation that can be given to the TOC is the same for organics. As mentioned high TOC content gets linked to the abundant presence of petroleum hydrocarbons, which have naturally high content of carbon in its composition. The importance of the COT is that it is involved in the processes of adsorption-desorption of contaminants since it is part of the organic matter such as colloidal humus. The latter and clays, tend to retain the polluting hydrocarbons in the soil, particularly non-polar hydrocarbons such as the majority of the PAH.

The cation exchange capacity is important from the point of view of soil pollution. It refers to the ability to have the minerals from the soil, basically by clays, to retain cations or polar organic molecules as the BTEX and some PAH, and which can be adsorbed to fine particles. Under this concept, the average of $12.04 \mathrm{Cmol} / \mathrm{kg}$ for sediment in $\mathrm{PM}$ and $6.41 \mathrm{Cmol} / \mathrm{kg}$ for sediment in PE, classified them with low adsorption capacity of cations and polar compounds $(<15 \mathrm{Cmol} / \mathrm{kg}$ ) (Muñoz, 2007).

This corroborates the texture of sediments and soil, which are formed in greater proportion very low percentage of clays and sands. From the point of view of transport of pollutants, the interchangeability and the presence of organic matter represent adsorption/desorption of contaminants power electronegative surface minerals and soil humus. Both the percentage of organic matter and the composition of the clay in soils play an important role in the retention of pollutants such as hydrocarbons and metals. 
With regard to porosity it is a mathematical relation between the particle density and bulk density and represents the spaces between soil particles. These spaces can be occupied by air, water and at a given time by contaminants and in particular by large molecules, as it is the case of PAH. The pores of the soil, can have different sizes, in such a way that they influence the speed at which water moves through the same (permeability).

The average value of porosity in the sediments of the dam (MW) is $28.36 \%$, in this case, the porosity is given by the soil particles and the presence of hydrocarbon weathering. In the case of the sediments of the EW, the average porosity was $60.66 \%$ which is given mainly by the presence of sand in the soil. In terms general the sediments of the exploratory wells presented greater permeability.

The global average of $\mathrm{pH}$ so much of the sediment of MW and EW, is 8.43, which turns out to be alkaline and are not saline. The sediments have high content of organic matter due to the presence of hydrocarbons and this is reflected in a high total organic carbon content, while soils are poor in organic matter and therefore has low total organic carbon, since its texture is sandy. The material has a low cation exchange capacity which translates into a low capacity to retain organic compounds. The porosity of the sediment (MW) is of $28.36 \%$ at the dam and $60.66 \%$ for the PE, the latter can be reflected in a high hydraulic conductivity.

The results of BTEX and PAH in sediments wells dam of benzene, toluene, ethylbenzene and Xylenes in the sediments from four wells (PM1, PM2, PM3 and PM4,) sampling at different depths located within the dam, for the most part show that there is no detected levels of these compounds, except in the MW2 well, shows MW2 level 1. These p-Xylene at a concentration of 2,171 mg/kg in the 0 to 1 m. layer was detected In the same well shows MW2 level 2 of depth is detected Ethylbenzene with $0.845 \mathrm{mg} / \mathrm{kg}, \mathrm{m}, \mathrm{p}$-Xylene with $3.271 \mathrm{mg} / \mathrm{kg}$ and o-Xylene with $1.816 \mathrm{mg} / \mathrm{kg}$. Not exceed the maximum permissible limits according to NOM-138-SEMARNAT/SS-2012 [17].

In the upper layers of the well was where was detected the presence of these monoaromatics hydrocarbons (BTEX) as shown in Figure 3.

Naphthalene has a special group of PAH role since it is much more soluble and volatile than the rest of this group. The mobility of the naphthalene is much greater than the PAH and diesel. PAH are lipophilic or hydrophilic properties and are easily adsorbed on soil organic particles. The water solubility and volatility is very low. The mobility of these compounds decreases as you increase the number of benzene rings.

PAH can be dragged into the groundwater when they are absorbed in colloids and they are washed away by rain infiltration or dissolve in the leachates of soil by use of tensoactive. In this way, PAH even 4- and 5-ring can be found in groundwater, but in very small quantities. In terms of the results of $16 \mathrm{PAH}$ of toxicological and environmental importance, detected the presence of naphthalene, Acenaphthene, Fluorene, Phenanthrene, and Pyrene in 4 wells sampling MW1, MW2, MW3 and MW4 (within the dam cuts), in the upper strata of sediment ranging from surface and up to 2 meters of depth. Specifically in the sediment of the well of sampling MW3, to a depth of 1 to 1.35 meters, not is detected naphthalene, while in the other wells (MW1, MW2 and MW4) itself was detected (Figure 3).

\section{MW 1}

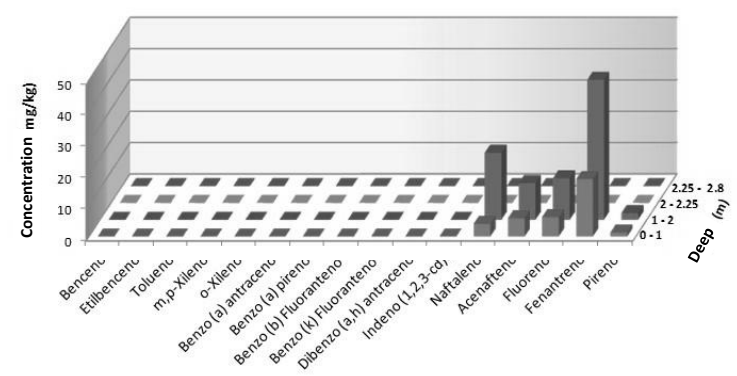

\section{MW-2}

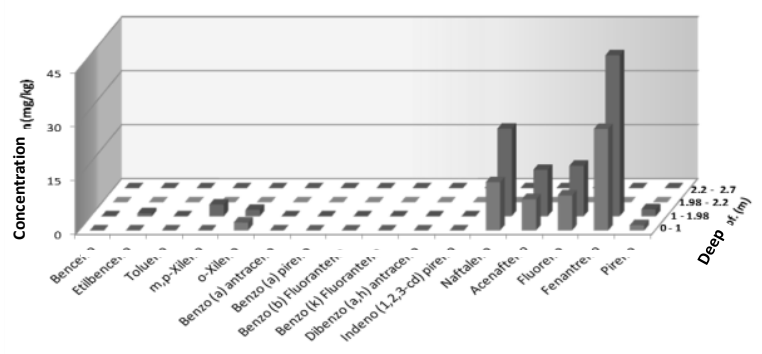


MW 3

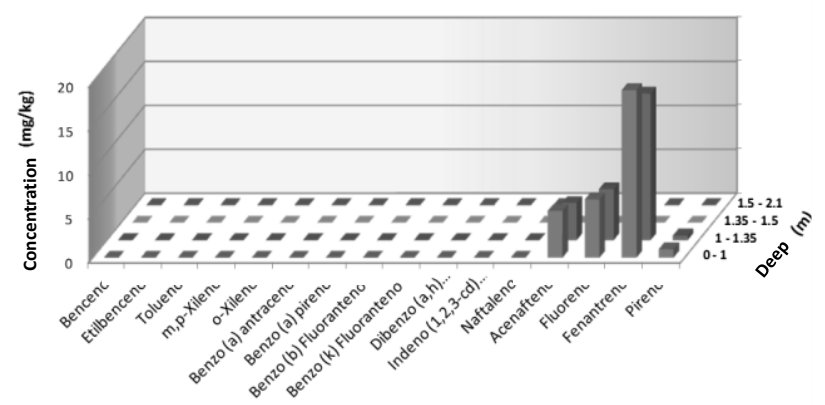

MW-4

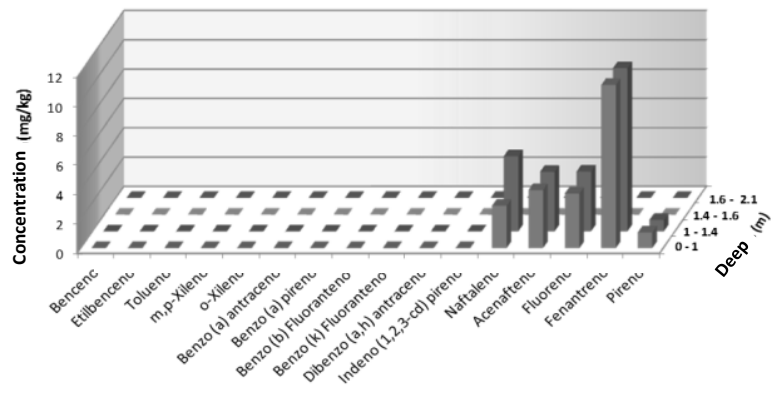

Figure3. Content of BTEX and PAHS in sediments to the different depths in the well of sampling MW1, MW2, $M W 3, M W 4$. The values of PAH present differences significant statistics between the depths $(p<0.05)$.)

The average values of the four wells in the 0 to $1 \mathrm{~m}$ depth stratum were; Naphthalene is 5.09, 5.95 Acenaphthene, Fluorene 6.57, 19.20 Phenanthrene and pyrene $1.19 \mathrm{mg} / \mathrm{kg}$. With the average values in the layer to a depth of 1 and up to $2 \mathrm{~m}, 12.738 .24$ for Acenaphthene, Naphthalene, 9.31 for Fluoranthene, 29.33 for Phenanthrene and Pyrene to $1.34 \mathrm{in} \mathrm{mg} / \mathrm{kg}$. In the lower layers of each well to a depth of average $2.5 \mathrm{~m}$, no concentrations of PAH were detected.

This is also due to the effect of formation of a colloid with composite hydrocarbon called resins that stayed in your matrix to this type of PAH. While other fractions called hydrocarbons asphaltene precipitated, thus producing the effect or phenomenon of plaster, at the bottom of the dam, which avoided the process of leaching to lower tiers, and causing the entrapment of hydrocarbons contained in drilling cuts [18].

Not were detected none of them compounds of PAH regulated in the NOM-138-SEMARNAT / SS2012, between which is found: Benzo [to] pyrene, Dibenzo [to, h] anthracene, Benzo [to] anthracene, Benzo [b] fluoranthene, Benzo [k] fluoranthene, Indene (1,2,3-cd) pyrene (SEMARNAT, 2012). These compounds with strong potential carcinogenic, to difference of them compounds that were detected in this study and that not are classified of this form by the Agency International of research in Cancer of the WHO[19].

On the other hand the presence only of naphthalene, Acenaphthene, Fluorene, Phenanthrene, and Pyrene in the sediments, i.e. PAH with less than 4 aromatic rings, confirms that the source of this type of PAH is exclusively petrogenic. And that is not associated to possible activities or pyrogenic residues, corresponding to PAH with more than 5 aromatic rings [20].

The analytical results in sediments of exploratory wells showed are not detected none of the BTEX and $16 \mathrm{PAH}$ of environmental interest to this study [Fig. 3]. This fact is crucial to confirm that transport of hydrocarbons from the dam into the surrounding areas there is not, and that together with the evidence of the physical and chemical parameters of the sediments and soils evaluated. Because be inferred that a series of processes joining on the site of different kinds such as weathering of the cuts, both physical chemical and biological. The separation of fractions of hydrocarbons by their structure and density, causing the precipitation of fractions heavy as the asphaltenes at the bottom of the dam. Meanwhile another lighter hydrocarbon fraction called resins formed a colloid that hold back small amount of BTEX leaving them in a top tier of the dam.

The analytical results in water of exploratory wells showed that these compounds not were detected both BTEX and PAH, suggesting there is no transport underground or surface of such compounds, from the dam cuts into surrounding areas [Fig. 3].

BTEX and PAH were not detected in soil, or in water coming from the exploratory wells (adjacent to the dam, waste), this means that there is no transport of hydrocarbons by advection (groundwater flow) from the dam to neighbouring areas. This was corroborated with the wells from the dam, this shows that the hydrocarbons are retained in the sediment weathered and hosted within the dam.

The process of adsorption is the process that determines and controls of form important the dispersion of the pollution of soils and sediments of the compounds organic e hydrocarbons petrogenics. The 
most important processes that determine the behavior of PAH in soil and its availability for transformation are the adsorption on solid ground and desorption to the aqueous phase [21].

The fraction organic of the soil is responsible of the adsorption of compounds hydrophobic, many PAH and others pollutants not polar are absorbed mainly by matter organic rather than by them clays. The retention of compounds is directly linked to the partition coefficient octanol-water (Kow) compounds and soil organic carbon content. In the case of Anthracene, was demonstrated that a soil with an organic carbon content of greater than $2 \%$, the retention is evident after 200 days of weathering [22].

The PAH present in the soil and sediment often is divided in different fractions that affect to its bioavailability: susceptible to them losses (easily removable and bioavailable), labile / bioavailable (wrong removable) and with destination irreversible (not removable, not bioavailable). Due to their high affinity of adsorption by the organic matter of the soil, PAH most accumulate in the upper layer of the soil and the reduction of its contents with soil depth [22].

Descriptors transport in soil environmental factors are related, the dispersion of PAH in soil without vegetation are: cation exchange capacity, area of surface, mineralogy and clay content, structure of pores, aggregation, temperature, moisture content, content of nutrients and organic fertilization.

Given the lithological and stratigraphic characteristics of the site described above, expected sizes of well selected dominantly coarse grain at least in the first $5 \mathrm{~m}$ of depth, shoelaces or coastal bars. Percentage distributions of sand, silt and clay, without specifying the actual grain size, for what is estimated the likely distribution of the grading curve average of three samples based on the percentages.

The phenomenon of seal or sealing of pores in the walls and floor of the dam, mainly caused by the same hydrocarbons PAH, referred to as plaster or plaster wall or training [23]. This phenomenon is largely caused by the tendency of fine particles of mud that pass through the porous medium of the formation, these particles accumulate in the pore throats until they manage to form the plaster, which reduces considerably the filtering of fluids of hydrocarbons towards forming a seal on the wall of the dam.

Permeability in the plaster is, of course influenced by the type of colloid, quantity and particle size. For example plasters them bentonite are common, it has low permeability because they are flat, by its particularity in the form of platelets which allow a good package in the direction of flow [23]. Assuming that the contaminated soil could cover vast areas and that did not occurred dilution, as a stage in the worst case, the EC both in surface and ground waters due to drainage, runoff and percolation, were estimated from the concentration in the pore water.

\section{Conclusions}

Within the dam the values of BTEX registered, arose in the MW2 well at levels 1 and 2 deep. PAH levels only were detected in waste dam the following maximum concentrations: Naphthalene 24.3, Acenaphthene 129, 14 Fluorene, Phenanthrene 44.7 and Pyrene 2 in $\mathrm{mg} / \mathrm{kg}$. Meanwhile in the outer area adjacent to the dam was not detected the presence of BTEX or PAH in samples of sediment and groundwater in exploratory wells, so does pollution in the periphery to the dam.

With regard to the presence of contaminants environmentally critical, is found predominantly PAH, that not are regulated by the NOM-138-SEMARNAT/SS-2012 and a small lens with BTEX within it dam of cuts. These are practically immobilized, since not exists evidence of mobility effective current, of some type of these pollutants, in accordance with them analysis chemical practiced of them samples of them wells of exploratory, both in sediment as in water table, which not presented any of these types of hydrocarbons.

There isnot present transport of PAH and BTEX compounds through the movement of groundwater, because of three processes that might occur:

The phenomenon of seal or sealing of pores in the walls and floor of the dam, mainly caused by the same hydrocarbons PAH, referred to as plaster or plaster walls (Martinez, 2011). This phenomenon is largely caused by the tendency of fine particles of mud that pass through the porous medium of the formation, these particles accumulate in the pore throats until they manage to form the plaster or plugged to reduce considerably the filtrate to formation forming a seal on the wall of the dam. 
Weathering of hydrocarbons from cuts of oil drilling that basically to degradation by environmental factors such as solar radiation, rainfall, temperature gradients, microbial action among others, which in turn generate changes not only physical i.e. phases from State, but also chemical structure and composition in the mass of cuts and own oil impregnated in them.

The state physics changes in the mass of impregnated with oil cuts, is gave way to the processes of formation of colloids based on resins, lower density, so it remained in the upper strata of the dam. On the other hand precipitated asphaltenes hydrocarbons, due to its greater density, leaving mainly distributed in strata from the bottom of the dam. Being both very viscous hydrocarbon fractions by what did not step or flow or transport them and nor light fractions trapped in them, as in the case of group of mononuclear hydrocarbons (BTEX) and polynuclears (PAH). These conditions the dam are constituting a hydraulic barrier to the step of flow of the groundwater, so that flow of the area that is configured, not only is diverts by the barrier, also loses it speed of flow between the exploration wells.

Finally these processes producing an effect of trapping of these materials in the oil drilling cuts dam, a situation that has avoided adverse effects on the environment directly and indirectly to the biota in the area.

\section{ACKNOWLEDGEMENT}

Financial and material support for this study was provided by PEMEX and Instituto Mexicano del Petróleo. R. Uribe-Hernández is grateful for SNI fellowship.

\section{REFERENCES}

[1] Douglas, G., Bence, A.E., Prince, R., Mcmillen, S. and Butler, E., Environmental stability of selected petroleum hydrocarbon source and weathering ratios: Env. Sci. Tech., 30, 2332-2339. (1996).

[2] Stroo, H.F., Jensen, R., Loehr R.C., Nakles D.V., Fairbother A.F., Liban C. B., Environmentally Acceptable Endpoints for PAHs at a Manufactured Gas Plant Site, Env. Sci. Thec., 34, 38313836 (2000).

[3] International Petroleum Industry Environmental Conservation Association (IPIECA), Drilling fluids and health risk management; A guide for drilling personnel, managers and health professionals in the oil and gas industry. London SE1 8NL, United Kingdom. International Association of Oil \& Gas Producers (OGP), 60 (2009).

[4] Hernández Trejo J. A., Análisis de los fluidos de perforación en la industria petrolera, Universidad Veracruzana, Tesis de la Facultad de Ingeniería Mecánica Eléctrica, 109 p.(2010).

[5] Secretaria de Medio Ambiente y Recursos Naturales (SEMARNAT. Ley General para Prevención y Gestión Integral de Residuos (LGPGIR). Diario Oficial de la Federación el 22 de mayo de 2015. 52 p (2014).

[6] Toledo-Sánchez, H.M. Fragilidad, vulneravilidad y riesgo en la cuenca baja del sistema GrijalvaUsumacinta. Tesis profesional, ESIA-IPN, 143 pp (2011).

[7] Comisión Nacional del Agua (CONAGUA), 2009, Actualización de la disponibilidad media anual de agua subterránea. Acuífero (2704) Centla, Estado de Tabasco. Subdirección general técnica. Gerencia de aguas subterráneas, 13 p.

[8] Instituto Nacional de Estadística, Geografía e Informática (INEGI), Perspectiva Estadística del Estado de Tabasco. 175 p. (2000).

[9] Muñoz Iniestra M., Edafología: manual de prácticas. Universidad Nacional Autónoma de México. Fac. de Estudios Superiores Iztacala. 3ra ed. 82 p. (2007).

[10] Álvarez, Jr. M., 1961, Provincias Fisiográficas de la República Mexicana. Boletín de la Sociedad geológica Mexicana, Vol. 24, no. 2, 4-20 p. (1999).

[11] Hori, K. y Saito, Y. , Classification, architecture and evolution of large river deltas in Gupta, A., Ed., Large Rivers: Geomorphology and Management. John Wiley \& Sons, Ltd., 75-96 (2007).

[12] Unites States Environmental Protection Agency (USEPA), Method 8270C, Semivolatile Organic Compounds by Gas Chromatography/ Mass Spectrometry (GC/MS): Test Methods for Evaluating Solid Waste, Physical/Chemical Methods (SW-846). US EPA Washington, DC, EPA. (1986). 
[13] Unites States Environmental Protection Agency (USEPA), Method 3050b: Acid digestion of sediments, sludges and soils. (SW-846), Washington, D.C., Environmental Protection Agency Publication, US EPA Washington, DC. (1996).

[14] Unites States Environmental Protection Agency (USEPA), Method SW-846, Test Methods for Evaluating Solid Waste: Physical/Chemical Methods, 3rd ed., September. US EPA Washington, DC. (1988).

[15] Secretaria de Medio Ambiente y Recursos Naturales (SEMARNAT), Norma Oficial Mexicana que establece las especificaciones de fertilidad, salinidad y clasificación de suelo. Estudios, muestreos y análisis (NOM-021-RECNAT-2000) Diario Oficial de la Federación, martes 31 de diciembre de 2002. 42 p. (2000).

[16] SPSS, SPSS Professional Statistics (CD-ROM): Chicago, Illinois, SPSS Inc., 1 CDROM.(2011).

[17] Secretaria de Medio Ambiente y Recursos Naturales (SEMARNAT), NORMA Oficial Mexicana, que establece los Límites máximos permisibles de hidrocarburos en suelos y lineamientos para el muestreo en la caracterización y especificaciones para la remediación.( NOM-138-SEMARNAT/SSA1-2012) Diario Oficial de la Federación Martes 10 de septiembre de 2013. 16 p. (2012).

[18] Fontenot, K, Lesso B., Strickler RD., Warrem T., Perforación de pozos direccionales con tubería de revestimiento. Schlumberger, 5 p (2005).

[19] International Agency Research Cancer (IARC), Polynuclear Aromatic Compounds, Part 1, Chemical, Environmental and Experimental Data: IARC Monographs on the Evaluations of the Carcinogenic Risk of Chemicals to Humans, IARC, Lyon, France. 195 p. (1983).

[20] White, E., Xu, L., Lima, A.L., Eglinton, T. and Eddy, C., Abundance, composition, and vertical transport of PAHs in marsh sediments: Environmental Science Technology, 39, 8273-8280 (2005).

[21] Cornelissen, G., Vannoort, P.M., Govers H.A.J. , Mechanism of Slow Desorption of Organic Compounds from Sediments: A Study Using Model Sorbents Environ. Sci. Technol. 32: 31243131 (1998).

[22] Cousin, I. T., Beck, K. and Jones, K. J., A review of the processes involved in the exchange of semi-volatile organic compounds (SVOC) across the air-soil interface, Sci. Total Environ. 228, 5-24 (1999).

[23] Martínez Fernández, J.R., Método de prueba para la determinación de la pérdida de filtrado dinámico a alta presión y a alta temperatura para fluidos de perforación base agua. Tesis Profesional. Facultad de Ingeniería, UNAM. 109 p(2011) 